\title{
STUDY OF THE REMOVAL OF 4-NITROPHENOL FROM AQUEOUS MEDIA BY ADSORPTION ON DIFFERENT MATERIALS
}

\author{
C. MATUS ${ }^{*}$, E. CAMU' ${ }^{1}$, M. VILLARROEL ${ }^{2}, J . O J E D A^{3}$, P. BAEZA ${ }^{1}$ \\ ${ }^{1}$ Pontificia Universidad Católica de Valparaiso, Facultad de Ciencias, Instituto de Química, Casilla 4059, Valparaíso, Chile. \\ ${ }^{2}$ Universidad de Santiago de Chile, Facultad de Química y Biología, Casilla 40, Correo 33, Santiago, Chile. \\ ${ }^{3}$ Universidad de Valparaíso, Facultad de Farmacia, Casilla 5001, Valparaiso, Chile.
}

\begin{abstract}
The removal of 4-Nitrophenol (4-NP) from aqueous media by adsorption is studied in a batch system using different porous materials: activated carbon, zirconia, alumina, sepiolite, natural zeolite and $13 \mathrm{X}$ zeolite. Depending on their adsorption capacities, the best adsorbent was chosen to be impregnated with different levels of nickel $(\mathrm{Ni})$ in order to study the adsorption by $\pi$-complexation in batch and continuous systems. The samples of $\mathrm{Ni}(\mathrm{x}) /$ support $(\mathrm{x}=2,4,6 \%)$ were prepared by wet impregnation and were characterised using the same method as with all the materials, by $\mathrm{N}_{2}$ adsorption-desorption using the BET method, surface acidity and Z potential measurements by electrophoretic migration. The samples were measured in a UV-Vis electrophotometer at a wavelength of 318 $\mathrm{nm}$, while the adsorption capacity of the material in the batch system was determined by calculating the difference in concentration once the adsorbent became saturated after an initial concentration of $\sim 20 \mathrm{ppm}$, and in the continuous system this was done by integrating the area under the adsorption curve. The results suggest that adsorption capacity depends on the specific BET area, apparent acid strength and the IEP of each support, and that it varies with the addition of Ni.
\end{abstract}

Keywords: Adsorption, 4-Nitrophenol, supports, $\pi$-complexation.

\section{INTRODUCTION}

In Chile, agriculture and forestry are highly productive economic activities involving anthropogenic factors that affect the quality of surface water courses and bodies through the use of fertilisers and pesticides. This is because approximately $90 \%$ of farming fields have these components added, mainly in the form of organophosphate pesticides, which are known to be less persistent than organochlorines ${ }^{1}$. However, partial degradation of this type of pesticide generates by-products of higher toxicity than the initial compound ${ }^{2}$. This is the case with methyl-parathion (commercial name: Nitrox-80) which is moderately adsorbed onto surface soil particles, whereupon it may degrade naturally by biodegradation or chemical photolysis or hydrolysis ${ }^{3}$, thus creating the by-product 4-Nitrophenol (4-NP).

Considering that different natural degradation processes can simultaneously act on the degrading compound and on different points on its structure, knowledge of these transformation reactions remains in its initial stages. However, more than $50 \%$ of the initial compound of 4-NP is degraded in approximately three weeks by any natural process acting upon it ${ }^{4}$.

Nitroaromatic compounds are generally highly toxic and are classified as hazardous ${ }^{5}$ due to their mean lethal concentration $\left(\mathrm{LC}_{50}\right)$. They therefore belong to the group of the eleven most pollutant phenols described by the $\mathrm{EPA}^{6,7}$. In addition, most of these compounds are deposited in water and soil, including rainwater $^{8}$, wastewater effluent from various industries ${ }^{9}$ and drinking water. In humans, most nitrophenols are absorbed through the skin, the gastrointestinal tract or the lungs through inhalation of fine droplets ${ }^{10}$. Their removal from the body is slow and the half-life in humans has been documented at 5 to 14 days ${ }^{11}$.

Several methods have been reported for the degradation or removal of 4-NP in aqueous media, giving high levels of purity to the waters. They are known as Advanced Oxidation Technologies (AOT) ${ }^{12}$. Though these technologies lead to the formation of an oxidising radical, each of these processes requires various conditions in order to remove the compound effectively. An example of this is Fenton's Process ${ }^{13}$ which requires strict $\mathrm{pH}$ control. These oxidation processes are used as pre-treatments for pollutants that are resistant to biodegradation, and they also use high amounts of reagents, while occasionally requiring high levels of energy consumption. For these reasons, they can have high operating costs. The use of adsorption to selectively remove 4-NP by $\pi$-complexation under ambient conditions is therefore an excellent option, since the metal cation can capture bonding electrons from the molecule in question, depositing them in its empty s orbital. In addition, its d orbitals can cede the electron density to the antibonding $\pi^{*}$ orbitals in the p orbitals of the aromatic ring of 4-NP. The cations that should have considerable adsorption capacity for this type of molecule have electrons on the $\mathrm{d}$ orbitals for electron donating and the $\mathrm{s}$ orbital is empty and can receive the electron density. $\mathrm{Cu}(\mathrm{I}), \mathrm{Ag}(\mathrm{I})$ and $\mathrm{Ni}(\mathrm{II})$ are therefore good options. Of these, the oxidised state of $\mathrm{Ni}(\mathrm{II})$ can be obtained simply by a process of calcination ${ }^{14-16}$.

\section{MATERIALS AND METHODS}

\subsection{Preparation of the adsorbents.}

For the study of $\mathrm{Ni}$ impregnation, the adsorbents were prepared by impregnation in excess solvent using $\mathrm{Ni}\left(\mathrm{NO}_{3}\right)_{2} \times 6 \mathrm{H}_{2} \mathrm{O}$ (Merck pa.) as the precursor salt. The percentage metallic content was set at 2,4 and $6 \% \mathrm{Ni}$. This was achieved by dissolving the necessary quantity of the precursor salt. Once the supports had been impregnated, the adsorbents were dried at $100^{\circ} \mathrm{C}$ for 12 hours and then calcined at $300^{\circ} \mathrm{C}$ for 4 hours in a muffle furnace.

\subsection{Characterisation of the adsorbents.}

In order to calculate specific BET area, 200 to $400 \mathrm{mg}$ of each sample was degassed at $120^{\circ} \mathrm{C}$ for 18 hours, attaining a final pressure of $1 \times 10^{-3} \mathrm{~mm} \mathrm{Hg}$. The subsequent analysis was carried out in a glass flask at the temperature of liquid nitrogen $\left(-196^{\circ} \mathrm{C}\right)$ using a Micromeritics ASAP-2010 nitrogen adsorption/ desorption volumetric instrument.

The surface acidity of the materials was measured by potentiometric titration $^{17}$. An amount of 100-150 mg of support sample with $100 \mathrm{~mL}$ of pure acetonitrile was mixed with $0.05 \mathrm{~mL}$ of titration solution, $0.05 \mathrm{~N}$ butylamine in acetonitrile. The mixture was shaken for three hours and the first reading was taken with a calibrated potentiometer. Neutralisation of acidic sites was obtained by adding $0.05 \mathrm{~mL}$ of titration solution per minute until no appreciable variation was seen in the potential readings.

The zeta potential was measured using a Zeta Meter Inc. instrument, model 3.0, with an automatic sample transfer unit. Approximately $30 \mathrm{mg}$ of support with $300 \mathrm{~mL}$ of $\mathrm{KCl} 10^{-3} \mathrm{M}$ solution were added. The $\mathrm{pH}$ was adjusted for each support with solutions of $\mathrm{NaOH}$ or $0.1 \mathrm{M} \mathrm{HCl}$, as required.

\subsection{Determining adsorption capacity.}

\subsubsection{Batch system.}

Approximately $500 \mathrm{mg}$ of support were added to $100 \mathrm{~mL}$ of synthetic aqueous solution containing $\sim 20 \mathrm{ppm}$ of 4-NP. The solution was shaken mechanically at room temperature for eight hours (until saturation of the adsorbent). During this time, a sample was taken every 40 minutes, with cycles of 10 minutes, rest and 15 minutes in the centrifuge. The 4-NP feed and the samples were measured in quartz cells using a UV-Vis spectrophotometer with a wavelength of $318 \mathrm{~nm}$. The amount of compound adsorbed was calculated by converting the measured absorbency into units of concentration using a simple calibration curve, taking into account that the difference between the initial concentration of the feed solution $\left(\mathrm{C}_{\mathrm{A}}\right)$ and that of the samples $\left(\mathrm{C}_{\mathrm{M}}\right)$ (i.e. $\mathrm{C}_{\mathrm{A}}-$ $\mathrm{C}_{\mathrm{M}}$ ) is the amount of compound adsorbed onto the material.

\subsubsection{Continuous system.}

Approximately $500 \mathrm{mg}$ of the best adsorbent in terms of the adsorption capacity measured in the batch system was placed into a Pyrex tube with a frit to hold the adsorbent. The sample was dried for an hour at $100^{\circ} \mathrm{C}$ with a flow of 
$20 \mathrm{~mL} \min ^{-1}$ of argon to eliminate impurities. The system was then left to cool until it reached room temperature.

A feed of $\sim 20 \mathrm{ppm}$ of 4-NP was circulated at a flow rate of $\sim 1.5 \mathrm{~mL}$ $\min ^{-1}$. Samples were taken every 5 minutes until saturation of the adsorbent. Both the feed and the samples were measured in quartz cells in a UV-Vis spectrophotometer at a wavelength of $318 \mathrm{~nm}$. The amount of compound adsorbed was calculated by converting the measured absorbance into units of concentration using a simple calibration curve, calculating the adsorbed fraction 1-( $\left.\mathrm{C}_{\mathrm{M}} / \mathrm{C}_{\mathrm{A}}\right)$. This value is graphed against the eluded volume per gram of adsorbent, giving the area under the curve and thus the adsorption capacity.

\section{RESULTS AND DISCUSSION}

\subsection{Effect of the nature of the support.}

The results for specific area $\left(\mathrm{S}_{\mathrm{BET}}\right)$, pore volume $\left(\mathrm{V}_{\text {pore }}\right)$, pore diameter $\left(\mathrm{D}_{\text {pore }}\right)$, acid strength, density of acidic sites and isoelectric point (IEP) for each of the materials in question are shown in Table $\mathrm{N}^{\circ} 1$.

Table $\mathrm{N}^{\mathbf{0}} 1$. Results for $\mathrm{S}_{\mathrm{BET}}, \mathrm{V}_{\text {poro }}, \mathrm{D}_{\text {poro }}$, acid strength, density of acidic sites and IEP for each material.

\begin{tabular}{|c|c|c|c|c|c|c|c|}
\hline Support & $\begin{array}{c}\mathrm{S}_{\text {BET }} \\
\left(\mathrm{m}^{2} \mathrm{~g}^{-1}\right)\end{array}$ & $\begin{array}{c}\mathrm{V}_{\text {mesopore }} \\
\left(\mathrm{cm}^{3} \mathrm{~g}^{-1}\right)\end{array}$ & $\begin{array}{c}\mathrm{V}_{\text {micropore }} \\
\left(\mathrm{cm}^{3} \mathrm{~g}^{-1}\right)\end{array}$ & $\begin{array}{c}\mathrm{D}_{\text {pore }} \\
(\mathrm{nm})\end{array}$ & $\begin{array}{c}\text { Acid Str. } \\
(\mathrm{mV})\end{array}$ & $\begin{array}{c}\text { Density of acidic } \\
\left.\text { sites (meq } \mathrm{g}^{-1}\right)\end{array}$ & $\begin{array}{c}\text { IEP } \\
(\mathrm{pH})\end{array}$ \\
\hline Activated Carbon & 690 & 0.03 & 0.30 & 3.5 & -152.2 & 1.67 & 3.67 \\
\hline 13X zeolite & 186 & 0.02 & 0.08 & 36 & -105.4 & 0.39 & 3.10 \\
\hline Sepiolite & 245 & 0.16 & 0.11 & 4.1 & 40.6 & 0.86 & 2.60 \\
\hline Alumina & 205 & 0.35 & 0.09 & 6.8 & -51.8 & 1.62 & 8.14 \\
\hline Natural Zeolite & 62 & 0.02 & 0.03 & 36 & -40.3 & 0.68 & 3.05 \\
\hline Zirconia & 258 & 0.35 & 0.12 & 3.7 & 176.5 & 2.63 & 5.65 \\
\hline
\end{tabular}

Activated carbon clearly has the largest area by far with $690 \mathrm{~m}^{2} \mathrm{~g}^{-1}$ and it doesn't have high pore volume and pore diameter, as shown by the type of $\mathrm{N}_{2}$ adsorption isotherm. As with the other supports, activated carbon presented a type IV isotherm, characteristic of mesoporous solids (diameter between 2 $\mathrm{nm}$ and $50 \mathrm{~nm}$ ). However, it was the only material with a clear trend towards microporosity, given the volumes of the meso and micro-pores, which are responsible for this classification. With regard to the other supports, which all possess relatively similar specific BET, zirconia $\left(258 \mathrm{~m}^{2} \mathrm{~g}^{-1}\right)$ showed highly varied textual properties depending on the calcination temperature, with higher calcination temperatures decreasing the specific BET area and the pore size ${ }^{18}$. This support has higher total pore volume (the sum of meso and micro-pore volumes: $0.47 \mathrm{~cm}^{3} \mathrm{~g}^{-1}$ ), but it does not have high pore diameter, as do natural and $13 \mathrm{X}$ zeolites. This is related to the hysteresis loop, which was of the $\mathrm{H}_{3}$ type for the zirconia and for the zeolites and sepiolite. Though the zeolites have pore diameters of the same size, $36 \mathrm{~nm}$, due to their similar nature, they differ in area and in pore volume as a result of the different molar $\mathrm{Si} / \mathrm{Al}$ ratio between the two. The alumina has the fourth highest specific BET area and a high pore volume, and also has the second highest pore diameter after the zeolites.

For the apparent acid strength, the activated carbon has very weak acidic sites and its acidic site density shows that there are few potentially acidic groups on this support. The sepiolite has an acid strength corresponding to strong sites, which is expected considering that this metallic oxide contains silicon $(\mathrm{Si})$, which forms oxides that are more acidic than those formed by the aluminium (Al) in the alumina. The latter support has an apparent acid strength corresponding to weak sites due mainly to the lower electro-negativity of the $\mathrm{Al}$ atoms in comparison to $\mathrm{Si}$ atoms. The difference in acidic site density between the sepiolite and the alumina is due to the fact that alumina is formed not only of metal atoms but also surface hydroxyl groups. For the aluminosilicates, the natural zeolite has higher apparent acid strength (weak sites) than the $13 \mathrm{X}$ zeolite (very weak sites) due to the difference in the molar Si/Al ratio, which is lower for the $13 \mathrm{X}$ zeolite. This can also be seen with the acidic site density, which is lower for $13 \mathrm{X}$ zeolite due to the increased $\mathrm{Al}$ in its structure and to the rapid neutralisation of the few acidic sites present. The zirconia has a potential that corresponds to very strong sites, which is directly related to the calcination temperature: $300^{\circ} \mathrm{C}$ in this case. Under this condition, the highest degree of acidity and the highest acidic site density are obtained.

Finally, with regard to the surface charge of the materials, at $\mathrm{pH}$ levels below the IEP, the solids have a net positive charge and at $\mathrm{pH}$ levels above the IEP the solids are negatively charged. Considering this, and taking into account that the solution used in the study has a $\mathrm{pH}$ of 6.2 , it can be stated that the surface of the alumina will be positively charged, while all the other supports with have negative charge.

Figure $\mathrm{N}^{\mathrm{o}} 1$ shows that for the batch system all the materials in question, with the exception of zirconia (which is close to an experimental error), show some adsorption capacity for 4-NP and saturation times of above 80 minutes, considering equal adsorbent mass ( $\sim 500 \mathrm{mg})$, initial concentration (20 ppm) and analysis time (8 hours).
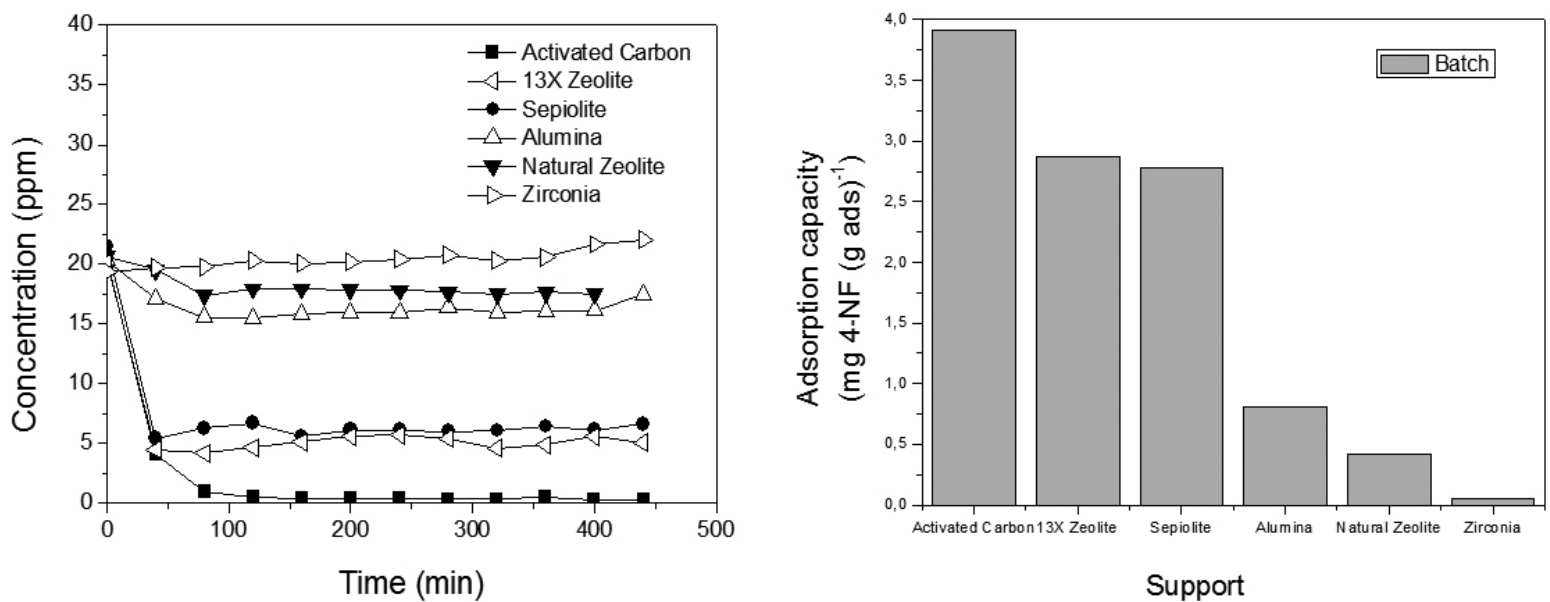

Figure $\mathbf{N}^{\mathbf{0}}$ 1. Adsorption curves for all supports using a batch system (left) and the adsorption capacity for each support (right). 
The materials that showed a trend towards microporosity (BET analysis), such as activated carbon, sepiolite and $13 \mathrm{X}$ zeolite, also showed the highest adsorption capacities in the same order (see right-hand graph in Figure $\mathrm{N}^{\circ} 1$ ). This can be explained by the dimensions of the 4-NP compound $(0.48 \mathrm{~nm} \times$ $0.62 \mathrm{~nm}$ ). The low adsorption capacities shown by the alumina and the zirconia are mainly due to their trend towards mesoporous volumes, and in the case of natural zeolite, this is principally due to the low specific BET area.

\subsection{Effect of adsorbent mass.}

Table $\mathrm{N}^{\circ} 2$ presents a comparative analysis of the masses and adsorption capacities obtained in the batch system, considering the initial mass of the adsorbent and the saturation time as parameters.

Table $\mathbf{N}^{\circ} \mathbf{2}$. Results for adsorption capacity in the batch system for activated carbon at different masses.

\begin{tabular}{|c|c|c|c|}
\hline Support & Ads Mass (g) & $\begin{array}{c}\text { Saturation time } \\
(\mathrm{min})\end{array}$ & $\begin{array}{c}\text { Ads Capacity } \\
\left(\mathrm{mg} \mathrm{g}^{-1}\right)\end{array}$ \\
\hline \multirow{4}{*}{$\begin{array}{c}\text { Activated } \\
\text { Carbon }\end{array}$} & 0.5013 & 160 & 3.92 \\
\cline { 2 - 4 } & 0.2508 & 280 & 7.67 \\
\cline { 2 - 4 } & 0.2007 & 280 & 9.66 \\
\cline { 2 - 4 } & 0.1460 & 320 & 12.42 \\
\hline
\end{tabular}

The masses were studied in order to select the optimal mass of activated carbon for impregnation with $\mathrm{Ni}$ given that activated carbon adsorbs around $20 \mathrm{ppm}$ when using $\sim 500 \mathrm{mg}$. Therefore, there is no reason to use a transition metal with this amount of mass, since the initial sample concentration was 20 ppm.

The 4-NP adsorption capacity results onto activated carbon using different masses clearly show that at lower mass there is higher adsorption capacity in terms of $\mathrm{mg} \mathrm{g}^{-1}$, though this is obtained at higher saturation times. This deviates from expectations, since adsorption capacity should normalise per $\mathrm{g}$ of adsorbent and should therefore be independent of the adsorbent mass used. This unexpected result is mainly due to diffusion problems, such as shaking, meaning higher efficiency is obtained when lowering the diffusion resistance in batch systems, leading to a more homogenous distribution of the 4-NP solution with the decrease in mass increasing contact between the solution and the adsorbent.

Figure $\mathrm{N}^{\circ} 2$ shows the effect of mass on the adsorption curves for activated carbon, justifying the use of a lower mass when conducting the Ni study to analyse possible changes in adsorption capacity and saturation times using this material.

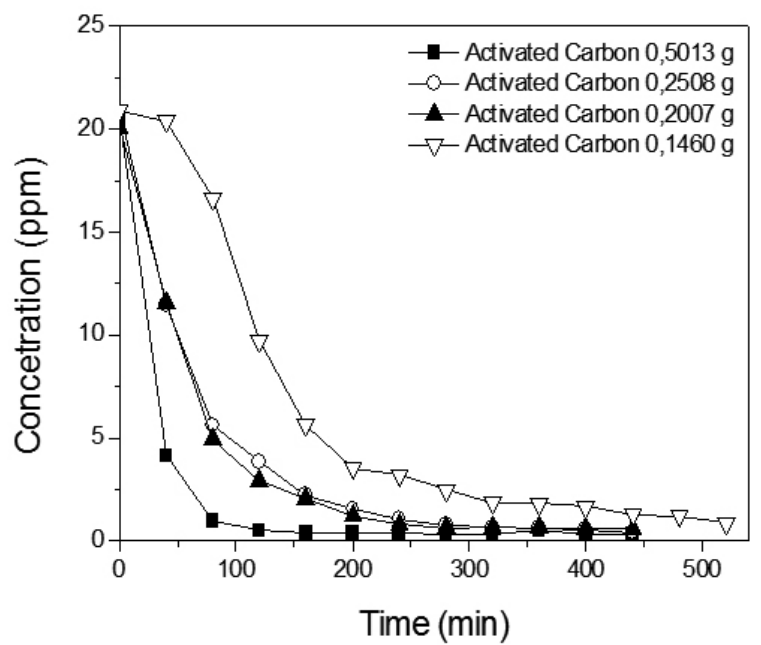

Figure $\mathbf{N}^{\mathbf{0}} 2$. Adsorption curves for different masses of activated carbon in the batch system.

3.3 Effect of Ni content on the adsorption capacity in batch and continuous systems.

The characterisation results for acid strength, acidic site density, isoelectric point (IEP), point of zero charge (PZC) and coated fraction $\left(\mathrm{X}_{\mathrm{w}}\right)$ for the best adsorbent and its respective metallic content and adsorption capacities are shown in Table $\mathrm{N}^{\circ} 3$.

Table No3. Results for characterisation and adsorption capacity in batch and continuous systems for activated carbon at different levels of Ni content.

\begin{tabular}{|c|c|c|c|c|c|c|c|}
\hline Samples & $\begin{array}{c}\text { Acid Str. } \\
(\mathrm{mV})\end{array}$ & $\begin{array}{c}\text { Density of } \\
\text { acidic sites } \\
\left(\mathrm{meq}^{-1}\right)\end{array}$ & $\begin{array}{c}\mathrm{IEP} \\
(\mathrm{pH})\end{array}$ & $\begin{array}{c}\mathrm{PZC} \\
(\mathrm{pH})\end{array}$ & $\mathrm{X}_{\mathrm{M}}$ & $\begin{array}{c}\text { Adsorption Capacity } \\
\left(\mathrm{mg}(\mathrm{g} \text { ads })^{-1}\right) \\
\text { Batch }\end{array}$ & $\begin{array}{c}\text { Adsorption Capacity } \\
\left(\mathrm{mg}^{\left.(\mathrm{g} \text { ads })^{-1}\right)}\right. \\
\text { Continuous }\end{array}$ \\
\hline $\mathrm{AC}$ & -152.2 & 1.65 & 3.67 & & & 12.42 & 5.45 \\
\hline $\mathrm{Ni}(2) / \mathrm{AC}$ & -109.6 & 1.93 & & 4.50 & 0.12 & 12.45 & 31.26 \\
\hline $\mathrm{Ni}(4) / \mathrm{AC}$ & -104.6 & 2.17 & & 5.76 & 0.31 & 12.48 & 27.01 \\
\hline $\mathrm{Ni}(6) / \mathrm{AC}$ & -57.1 & 1.12 & & 7.92 & 0.62 & 11.99 & 19.62 \\
\hline
\end{tabular}

AC: Activated carbon

$\mathrm{Ni}(\mathrm{X}) / \mathrm{AC}$ : Activated carbon impregnated by $\mathrm{X} \%$ of $\mathrm{Ni}(\mathrm{X}=2,4,6 \%)$.

For all the activated carbon adsorbents containing different levels of $\mathrm{Ni}$, an increase in acid strength from very weak sites to weak sites was seen with the increase in metal content. This is because Ni impregnation increase Lewis acidity, producing an increase in total acidity (Bronsted and Lewis), which is in turn identified by this method. It can also be deduced that the PZC values increase along with metal content, seen in the increase in coated fraction values, going from $12 \%$ of the surface covered in $\mathrm{Ni}$ on the activated carbon to $62 \%$ of the surface covered when the Ni content is raised to $6 \%$. It was also seen that above this percentage, the $\mathrm{Ni}$ is homogeneously spread over the surface of the activated carbon. These results are in agreement with those for acidic site density, which increase along with the metal content and only decrease with $\mathrm{Ni}$ content of $6 \%$, thus discarding the possibility that the metal is agglomerating on the surface. Therefore, the decrease can only be due to the metal covering the active sites. 

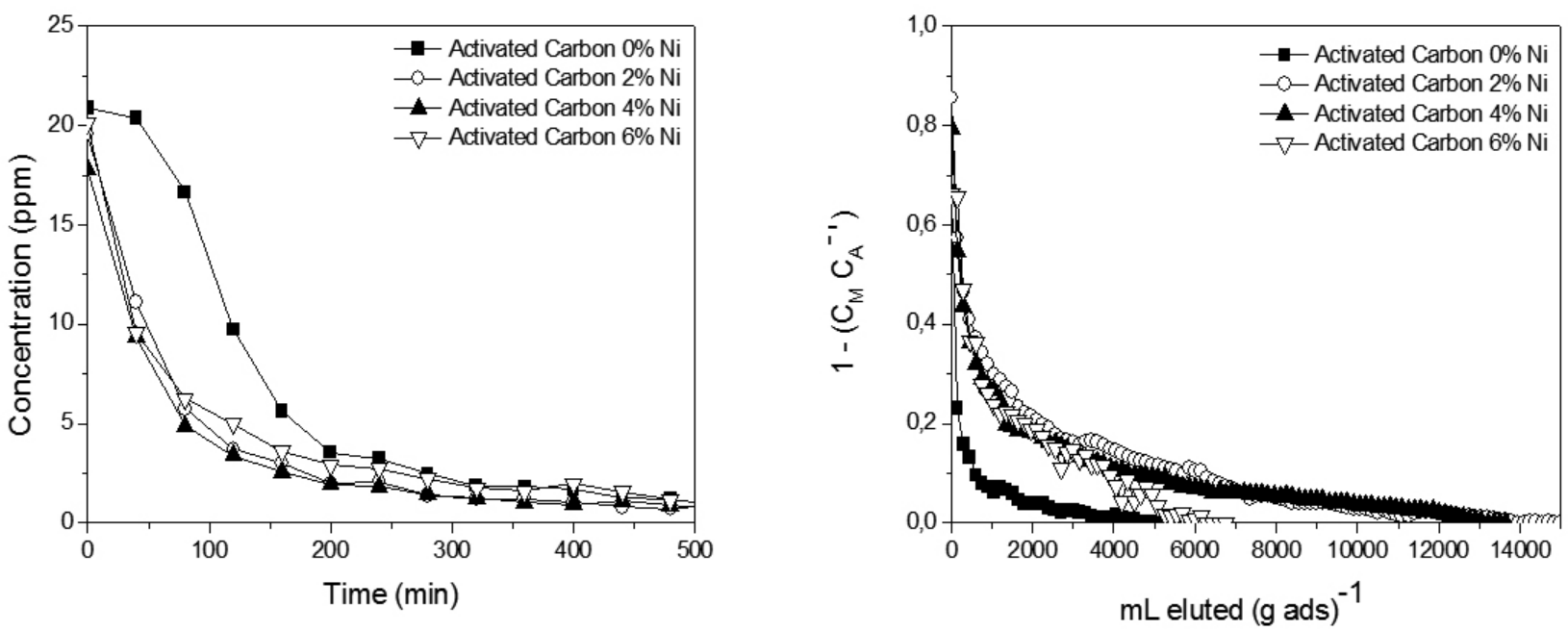

Figure $\mathbf{N}^{\mathbf{0}}$ 3. Adsorption curves for the batch (left) and continuous (right) systems.

Analysing the adsorption capacities in the batch system (Figure $\mathrm{N}^{\circ} 3$ left), it can be seen that the addition of metallic Ni did not increase adsorption capacity or reduce saturation times ( $\sim 320$ minutes) for any of the content levels, though this was observed in the continuous system (Figure $\mathrm{N}^{\circ} 3$ right). This is because in the latter system type diffusion phenomena were not observed due to

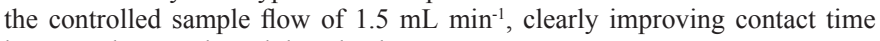
between the sample and the adsorbent.

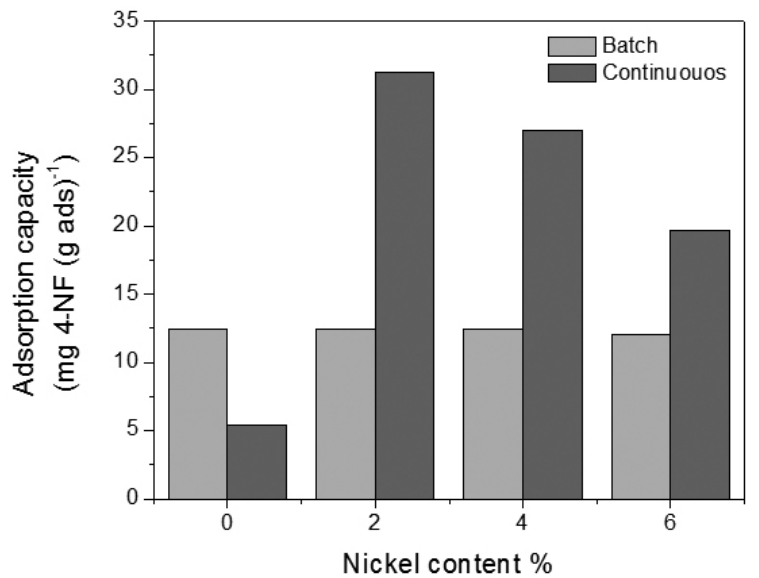

Figure No 4. Relation between metallic content and adsorption capacity.

Considering this, in a continuous system the activated carbon without impregnated metal has an adsorption capacity of $5.45 \mathrm{mg}$ of 4-NP (g ads $)^{-1}$, which is very low in comparison with the value obtained with the activated carbon impregnated with $2 \% \mathrm{Ni}$ (Figure $\mathrm{N}^{\circ} 4$ ), reaching $31.26 \mathrm{mg} 4-\mathrm{NP}$ (g $\mathrm{ads})^{-1}$. This increase can be attributed to the contribution of $\mathrm{Ni}$ to the adsorption through $\pi$-complexation. It can also be seen that with $4 \%$ metal content, the adsorption capacity does not increase from the value found with lower $\mathrm{Ni}$ content, which should have occurred based on all the previous characterization, since the Ni content was homogenously distributed over the activated carbon, as was verified by the increase in acid strength and the density of acidic sites. However, this leads to the conclusion that it is not necessary to apply higher $\mathrm{Ni}$ content levels when using a continuous system, since with the higher $\mathrm{Ni}$ content the saturation time and the negative surface charge of the adsorbents both decreased. The lower adsorption capacity for the $6 \%$ metal content level may be because the Ni blocks up active sites. This was also verified by the characterizations. With this level of metal content, the surface of the adsorbent has a positive charge and therefore the adsorption is no longer planar but axial along the 4-NP molecule. This is because the 4-NP compound concentrates higher electron density in the nitro group, and therefore adsorption cannot occur with this group, thus explaining the planar adsorption, due to the surface groups and the surface charge of the adsorbent. These results are in agreement with those presented by Kwon in a previous study ${ }^{19}$.

\section{CONCLUSIONS}

The study of adsorption capacity showed that though all the materials used in the study presented some degree of adsorption, the activated carbon was the best adsorbent, as it possesses a higher specific BET area, lower acid strength, and a surface that is negatively charged under the condition of this study, all of which contributes to planar adsorption of the 4-NP compound. In addition, impregnation with $\mathrm{Ni}$ leads to increased adsorption capacity by $\pi$-complexation in the continuous system. The level of metal content also plays an important role in the adsorption capacity for the best adsorbent, with an optimal content level that depends on the $\mathrm{X}_{\mathrm{M}}$.

Finally, removal of 4-NP by adsorption is shown to be a good alternative for the removal of priority phenolic compounds.

\section{ACKNOWLEDGEMENTS}

This work has been financed under FONDECYT project 1140808 . Donation of hydrous zirconium by MEL Chemicals is gratefully acknowledged and DI 125.760 Pontificia Universidad Católica de Valparaiso.

\section{REFERENCES}

1. Ramírez, J., Lacasaña, M., Archivo Prevención de Riesgos Laborales., 4(2), $67-75,(2001)$

2. Ferrusquía-García, C., Revista Latinoamericana de Recursos Naturales., 4(2), $285-290,(2008)$.

3. Cavoski, I., J. Agric. Food. Chem., 56(17), 8066-8073, (2008).

4. Wang, L., Chi, X., Zhang, J., Sun, D., Zhou, N., Int. Biodeterior. Biodegrada., 17, 116-121, (2014).

5. Goi, A.,Trapido, M., Adv. Environ. Res., 8, 303-311, (2004).

6. Realini, P., J. Chromatogr. Sci., 19(3), 124-129, (1981).

7. Shea, P., Weber, J., Review., 87, 1-41, (1983).

8. Rubio, M., Lissi, E., Herrera, N., Pérez, V., Chemosphere., 86(10), 1035 1039, (2012).

9. Parida, K., Prakasini, D. J., J. Photochem. Photobiol A., 163(3), 561-567, (2004).

10. Finkel, A., Herbicides: Dinitrophenols. In: Hamilton and Hardy's Industrial Toxicology, 4ta Edición, Boston, John Wright PSG, (1983), 301 .

11. Palmeira, C., Moreno, A., Toxicol Lett., 81,115-123, (1995).

12. Rafael Gómez Bachiller., Estudio de la degradación de Nitrofenoles mediante Fotocatálisis Heterogénea. Tesis (Licenciado en Química). Madrid, España, Universidad Carlos III, Departamento de Ciencias e Ingeniería de Materiales e Ingeniería Química, (2011), 65 h. 
13. Luis Alfredo Aznate Teheran/ Degradación por fotocatálisis (Foto-Fenton) de efluentes líquidos contaminados con residuos de fenol.Tesis (Ingeniero Químico). Cartagena de Indias D. T y C., Colombia, Universidad de Cartagena, Facultad de Ingeniería, (2013), 87 h.

14. Baeza, P., Aguila, G., Gracia, F., Araya, P., Catal. Commun., 9, 751-755, (2008).

15. Baeza, P., Aguila, G., Vargas, G., Ojeda, J., Araya, P., Appl. Catal., B
(111), 133-140, (2012).

16. Hernandez-Maldonado, A.J., Yang, R.T., AIChE Journal., 50(4), 791-801, (2004).

17. Cid, R., Pecchi, G., Appl. Catal., 14, 15-21, (1985).

18. Enríquez, J., Alamilla, R., García, U., Rodrigo, R., Quim. Nova., 36(7), 937-941, (2013).

19. Kwon, J., Wilson, L., J. Environ. Sci. Health., A (45), 1793-1803, (2010). 